\title{
Mediterranean Diet
}

\author{
Angelos K. Sikalidis *(D), Anita H. Kelleher and Aleksandra S. Kristo
}

Department of Food Science and Nutrition, California Polytechnic State University,

San Luis Obispo, CA 93407, USA; ahkelleh@calpoly.edu (A.H.K.); akristo@calpoly.edu (A.S.K.)

* Correspondence: asikalid@calpoly.edu; Tel.: +1-805-756-6496; Fax: +1-805-756-1146

\section{check for} updates

Citation: Sikalidis, A.K.; Kelleher, A.H.; Kristo, A.S. Mediterranean Diet. Encyclopedia 2021, 1,371-387. https:/ / doi.org/10.3390/encyclopedia1020031

Academic Editor: Harry H. X. Wang

Received: 19 February 2021

Accepted: 22 April 2021

Published: 25 April 2021

Publisher's Note: MDPI stays neutral with regard to jurisdictional claims in published maps and institutional affiliations.

Copyright: (C) 2021 by the authors. Licensee MDPI, Basel, Switzerland. This article is an open access article distributed under the terms and conditions of the Creative Commons Attribution (CC BY) license (https:// creativecommons.org/licenses/by/ $4.0 /)$.
Definition: The Mediterranean diet is a food pattern incorporated into a set of lifestyle practices typical of Greece and Southern Italy in the early 1960s, where adult life expectancy was notably high, while rates of diet-related chronic diseases were low. The Mediterranean diet was described initially by the work of LG Allbaugh, commissioned by the Rockefeller foundation and the Greek government post-WW2 on the Greek island of Crete in 1948. The Mediterranean diet was accepted as Intangible Cultural Heritage of Humanity by UNESCO in 2013. The primary advantages of the Mediterranean diet include health benefits pertinent to cardiovascular, metabolic syndrome, and cognition.

Keywords: Mediterranean diet; cardiovascular disease; cardiometabolic syndrome; UNESCO; Greece

\section{Introduction}

The Mediterranean diet gained international recognition due to Ancel Keys' work and was established as the original prototype for current dietary guidelines in the United States and other countries [1,2]. Among the earliest definitions of the Mediterranean diet is the one provided by Willet et al., whereby the Mediterranean diet (MD) reflects food patterns typical of certain regions of Greece and Italy in the early 1960s, where adult life expectancy was notably high, while rates of diet-related chronic diseases were low $[1,3]$.

In the US, the satisfying flavors, and hence a high acceptability of the Mediterranean diet, have been documented to provide opportunities for dietary improvement, such as increasing consumption of fresh vegetables, fruit, grains, and olive oil since the early 20th century [3,4]. Significant populations that immigrated to the United States from Greece, Italy, and Spain contributed to making the Mediterranean diet style more known in the US.

Currently, the Healthy Mediterranean-Style Dietary Pattern is included in the 20202025 version of the Dietary Guidelines for Americans in agreement with previous versions, as it is considered a variation of the Healthy US-Style Dietary Pattern, the latter based on the types and proportions of foods typically consumed by Americans [5], although in nutrient-dense forms and appropriate amounts [5]. In the manuscript herein, we provide an account on the historical timeline and main points of the Mediterranean diet, key studies that delineated its health benefits, and a contrast with main popular and widespread alternative dietary schemes.

While further research in delineating the mechanisms of the Mediterranean diet in protecting against chronic disease is required, the ways in which a palatable and healthful dietary pattern such as the Mediterranean diet can be promoted need to be investigated employing culinary and marketing strategies beyond medical and nutrition authorities [1,3].

The Mediterranean Sea (Figure 1) is linked to the Atlantic Ocean via the straits of Gibraltar (historically referred to as Pillars of Hercules) [6-8]. While the Mediterranean is almost completely enclosed by land-on the north by Europe (Greece, Adriatic countries, Italy, France, Spain), on the south by North Africa, and on the east by Anatolia and the Levant-the sea remains strictly a part of the Atlantic Ocean, though usually identified as a distinct body of water. From a geographical perspective, the Mediterranean is a broad region inhabited since the dawn of civilization on Earth, around a closed sea in the "middle of the earth" in an area with characteristic climate and soil conditions [6]. 


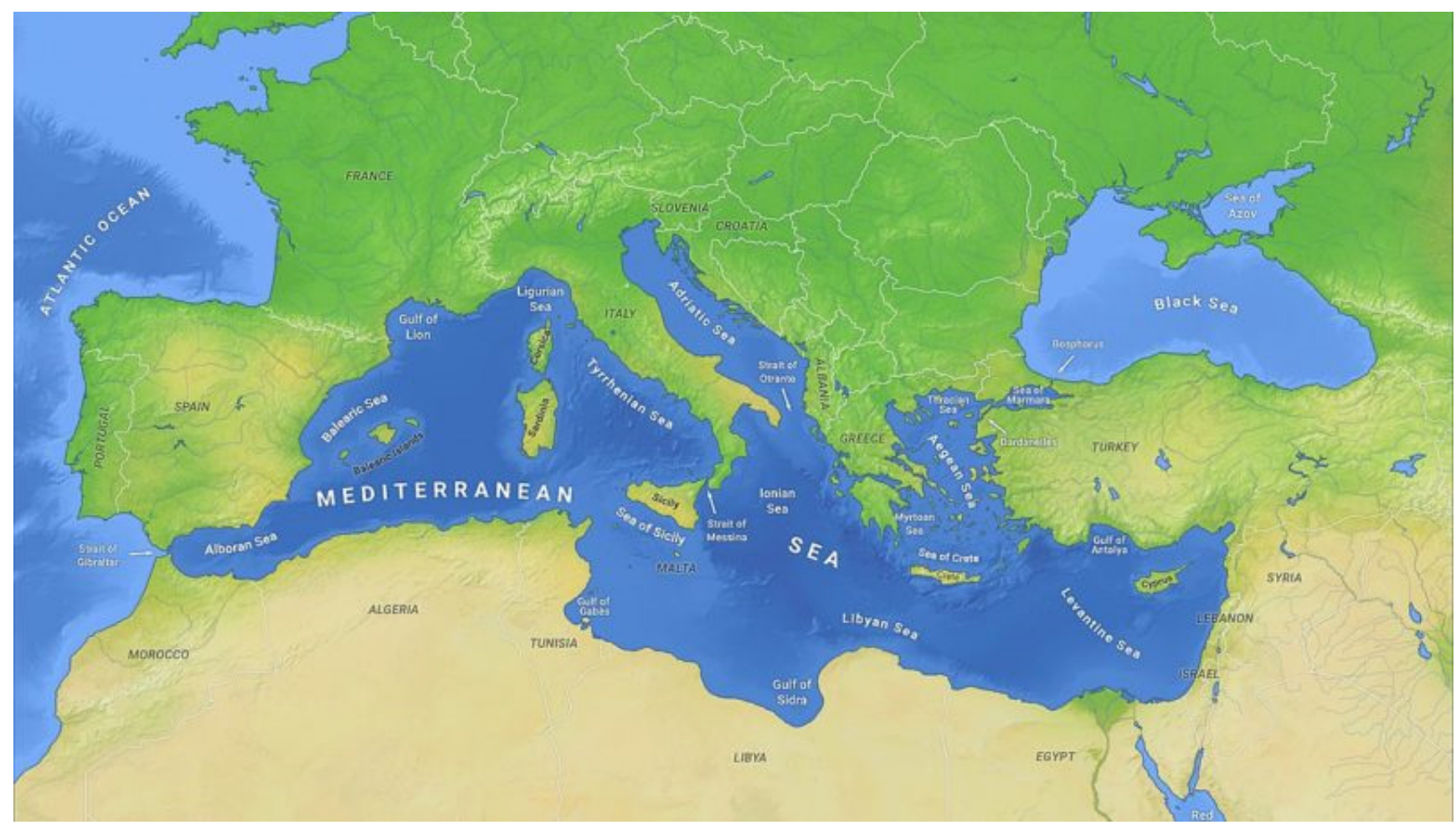

Figure 1. The Mediterranean Sea and region.

Concerning the climate of the area, this is characterized by normally hot, dry summers and mild, rainy winters. As far as the soil is concerned, particularly during the wet winters, there is leaching of clays and carbonates with the release of iron, which conveys a red color to the soil. Leaching is minimal throughout the dry summers; thus, there is typically an accumulation of a carbonate horizon in the soil. The climate and soil conditions of the Mediterranean are unusual in the world, since there are only limited areas in the US state of California, Australia, and Chile with what would be termed "the Mediterranean or Mediterranean-like" climate. Typical Mediterranean crops include olives and grapes (being the most characteristic), as well as oranges, tangerines, and cork, and a unique variety of herbs and spices. Ancient Greece was the cradle of the Mediterranean food tradition [9], while the basis of such tradition was characterized by the Mediterranean "eternal trinity" of wheat-olive oil-wine, enriched by a culture of sharing and commensality [9].

In Homeric times, salting for meats from cattle, sheep, and goats was employed as a method of preservation for these foods, which were important staples among the diets of aristocratic heroes; the specific portion/part of the meat served to an individual corresponded to their level of social status [6,8]. Similarly, to the Egyptians, the Greeks preferred the allium family, including onion, garlic, and leek. Other vegetables consumed included turnip, radish, lettuce, artichoke, cabbage, celery, cucumber, parsley, and thyme. Fruit involved dates (imported), figs, and grapes. The wealthy could procure walnuts and almonds from the East, while mushrooms and honey were accessible and fish was eaten fresh, dried, or pickled $[6,8,10]$. Tomatoes and potatoes were introduced much later in the region but were very quickly and massively adopted.

In the Mediterranean, the diet was typically built around plant-based foods, including vegetables, fruits, whole grains, nuts, and seeds. These provide antioxidants, significant amounts of fiber, as well as vitamins and minerals. Healthy lipids are another significant dietary benefit of MD, particularly those derived from olives, nuts, and fatty fish (such as salmon and sardines). These sources are all high in heart-healthy monounsaturated fat and are often used to replace saturated and trans fats found in fatty meats and cheese. There is also a low intake of saturated fats, which are often present in red meat, while moderate amounts of fish and poultry and lower levels of red meat are consumed. Dairy products are 
also moderately consumed. Moreover, spices and herbs are commonly used to flavor foods rather than salt, while moderate consumption of red wine with meals and desserts in the form of fresh fruit is habitually received [9-11]. From a dietary scheme perspective, when we refer to the term "Mediterranean diet" in the literature, further to the early definition Willet et al. provided, we primarily refer to the dietary pattern of South Italy (historically, Magna Graecia) and Greece (mainly Crete) at the time period of the 1950s-1960s [1,11-13].

Herbs and spices demonstrate key importance in the Mediterranean diet concept. Basil originates from Southern France and Italy. Oregano grows wild throughout the Mediterranean and is a cooking staple. Thyme originates in the Mediterranean and has a herbal, minty flavor. Cilantro has been found in both Southern Europe and the Middle/Far East. Chives belong to the onion family; however, they are milder than onions. Fennel originated in the Mediterranean. Onions are highly popular to Mediterranean cuisine since they enhance other flavors. Mint is used in Eastern Mediterranean cooking. According to Greek mythology, the word mint is derived from Minthe, a Greek nymph who was loved by Pluto and was changed into the peppermint plant. Other popular herbs and spices include cinnamon, cloves, bay leaves, and coriander. All the spices and herbs used are well-established, rich sources of phytochemicals and bioactive compounds that have been shown to produce significant health benefits $[6,10,13]$.

Olives and olive oil are central in the Mediterranean culture and diet. Greece was the first to start cultivation of the olive tree regularly in $3500 \mathrm{BC}$ (island of Crete). The olive tree was a central symbol in Ancient Greece, and olive oil was not only used for its valuable nutritional quality but also for medicinal and religious purposes. An olive tree branch wreath (kotinos-Greek: kó $\tau \iota v o \varsigma$ was awarded to the Olympic game winner along with olive oil- 5 tons for the first place. Olive oil is particularly rich in vitamin E, as well as in polyphenols, squalene, and iron [9,10]. Many herbs and spices can be added to olive oil to prevent oxidation and improve its flavor [6,8]. Descriptions from Homer and many depictions on pottery and frescos show clearly that people in the Mediterranean from ancient Greek times were knowledgeable over a variety of food preservation practices, including storage, salting, and/or seasoning for fish and seafood, olives and olive oil, wine, and various meats (such as pork, goat, sheep, and beef) [6].

Interestingly, the term diet is produced by the Greek " $\delta\left\llcorner\alpha \iota \tau \alpha \nu^{\prime}\right.$ ", meaning way of life [14]. Thus, the Mediterranean diet can be approached as a way of life incorporating but not limited to nutrition, developed and adopted by people in a geographical region populated since the early days of civilization on Earth, around a closed sea surrounded by land of characteristic climate and soil conditions. The Mediterranean diet portrays a "way of eating and cooking" which is unique because it is not merely healthy. The Mediterranean diet is proposed as a rather healthy way of eating. In this context, the Mediterranean diet was inscribed in 2013 on the Representative List of the Intangible Cultural Heritage of Humanity Countries: Greece, Italy, Spain, Morocco, Cyprus, Croatia, Portugal. The Mediterranean diet involves a set of skills, knowledge, rituals, symbols, and traditions concerning crops, harvesting, fishing, animal husbandry, conservation, processing, cooking, and particularly the sharing and consumption of food. Eating together is the foundation of the cultural identity and continuity of communities throughout the Mediterranean basin. It is a moment of social exchange and communication, an affirmation and renewal of family, group, or community identity [15].

\section{Identification of Mediterranean Diet-Specific Bioactive Compounds}

The Mediterranean region is characterized by a rich history of extensive food traditions dating back to antiquity. As olive trees originated and thrive in the area, olives and olive oil lie at the core of the food tradition. Other shared elements in the region are mostly plant-based such as grains, nuts, beans, and a wide variety of fruits and vegetables. The use of seafood and animal products (meat, dairy, eggs) varies broadly. Combined, consumption of some or all of these foodstuffs forms the commonly referenced Mediterranean diet. However, the Mediterranean diet is not a single diet, but rather a broad pattern of eating 
which applies to inhabitants in the countries bordering the Mediterranean Sea (approximately 20 countries) and those among regions within a country. Differences in agriculture production, economy, culture, ethnic background, and religion result in diversity in the diets consumed between these countries. For example, olive oil is the main cooking oil in Greece and Southern Italy, but not in France or Northern Italy where butter or lard are used for cooking, while olive oil is used mostly in salads.

What we know today as the Mediterranean diet is a modern concept. It is a nutrition guide, a set of dietary recommendations inspired by and based on traditional food patterns observed in the island of Crete and Southern Italy in the 1950s and 1960s. Something extraordinary was happening in these regions at that time. Despite the limited medical services, the rates of chronic disease among these populations were among the lowest in the world, and adult life expectancy was among the highest. The American physiologist Ancel Keys identified the connection between what people were eating and their low rates of disease and mortality in his Seven Countries Study, thus bringing the health benefits of the Mediterranean diet to light and attracting the attention of the modern scientific community $[5,11,15]$.

The Mediterranean diet became widely known to the public a few decades later, after a conference in Cambridge, Massachusetts (USA) in 1993, when the modern recommendations of the diet were represented visually with a pyramid graphic termed the MedDiet pyramid [16]. The Mediterranean diet of the early 1960s can be described by the following broad characteristics: an abundance of plant food (fruit, vegetable, breads, other forms of cereals, potatoes, beans, nuts, and seeds); minimally processed, seasonally fresh and locally grown foods; fresh fruit as the typical daily dessert, with sweets containing concentrated sugars or honey consumed a few times per week; olive oil as the principal source of fat; dairy products (mainly cheese and yoghurt) consumed daily in low to moderate amounts; fish and poultry in low to moderate amounts; $0-4$ eggs weekly; red meat in low amounts; and wine consumed in low to moderate amounts, normally with meals. This diet observed was particularly low in saturated fat (less than 7-8\%) while total fat intake ranged widely from less than $20 \%$ to more than $35 \%$ of total calorie intake, depending on the geographical region assessed. Physical activity was accounted for $[16,17]$.

The modern Mediterranean diet pyramid recommends the types and the frequency of foods that should be consumed daily, weekly, and monthly. Fruits, vegetables, grains (mostly whole), olive oil, beans, nuts, legumes, seeds, herbs, and spices are the foods every meal should be based upon. Fish and seafood should be consumed often, at least twice a week. Poultry, eggs, cheese, and yoghurt are consumed in moderate portions, daily to weekly. Meats and sweets are consumed less often. The MedDiet pyramid also provides a sense of proportions across a variety of different foods and emphasizes balancing energy intake from food with energy output through daily physical activity. The serving sizes, how much of each food should be consumed, need to be adjusted according to individual needs. Rather than a single food or nutrient emphasized, the dietary pattern is provided as a whole. It is not a restrictive diet where certain nutrients or foods are emphasized or omitted; hence, nutrient deficiencies linked to long-term restrictive diets can be prevented. The quality, rather than quantity, of nutrients is highlighted: unsaturated versus saturated fats, whole versus refined carbohydrate or sugar. It offers variety, taste, and satiety, making it easy to follow. The model also promotes natural versus processed foods, which can maximize the health-promoting micronutrient and antioxidant content of these foods [11,13]. Finally, the concept of the Mediterranean diet incorporates physical activity through performing daily chores, and a strong sense of community. These aspects of lifestyle are not directly associated with diet per se but do supplement the Mediterranean paradigm as a lifestyle that promotes health holistically.

\section{Mediterranean Diet Key Research Studies}

In 1948, the researchers of The Rockefeller Foundation became the first to explore the Mediterranean diet on the island of Crete in Greece. The researchers were invited 
by the Greek Government at the time in an attempt to help to improve the poor living conditions and enhance health for inhabitants of the island. They began their undertaking by thoroughly investigating the eating habits of Cretans and were surprised to discover that these habits were nutritionally sound, with minor exceptions in areas of low income and limited food production. According to the report: "olives, cereal grains, pulses, fruit, wild greens and herbs, together with limited quantities of goat meat and milk, game and fish consist the basic Cretan foods ... No meal was complete without bread ... Olives and olive oil contributed heavily to the energy intake ... food seemed literally to be 'swimming' in oil." The researchers concluded that no modification to the Cretan diet or eating habits was necessary as they were already surprisingly good, conducive to good heart health, and well adapted to the natural and economic resources of the area [18].

\subsection{Cardiovascular Disease Studies}

\subsubsection{The Seven Countries Study}

From 1958 to 1983, Ancel Keys and his international team worked laboriously on the Seven Countries Study. Together, they studied the diet and lifestyle factors, as well as the incidence of coronary heart disease, among approximately 13,000 randomly selected middle-aged men (40-55 years old) from seven countries: The United States, Japan, Italy, Greece, the Netherlands, Finland, and the geographic area/state that was then Yugoslavia. Data analysis revealed that in the Mediterranean regions (Greece and Southern Italy), where vegetables, grains, fruits, beans, and fish were abundant in a typical diet, heart disease was found to be rare. In the US and in Finland, the rates of heart disease were very high [18].

While Ancel Keys supported the undeniable role which diet played in the onset of coronary heart disease, he also insisted that diet was not the only factor involved. The people in the Mediterranean region, as assessed by the study, were physically active; family ties were strong; and the pace of life was more relaxed. These taken together, Keys concluded that even though diet was the single most important determining factor, it was ultimately a combination of dietary and lifestyle factors that were responsible for the remarkably low rates of heart disease in the Mediterranean $[18,19]$.

One particularly surprising finding of the Seven Countries Study was that Cretans consumed a significant proportion of their calories from fat, up to $40 \%$, yet they still had the lowest rate of heart disease and the highest average life expectancy in the world, alongside Japan. Ancel Keys determined that unlike saturated fat in meat and dairy, which is prevalent in American and Finnish diets, the majority of fat in the Cretan diet was derived from olive oil and fatty fish, which are rich in unsaturated fats.

\subsubsection{The Lyon Diet Heart Study}

The Lyon Diet Heart study was conducted among patients who had survived a first myocardial infarction between 1988 and 1992 [19]. The diet used in the study was created to mimic a Mediterranean-style dietary pattern. As such, it was notably high in omega-3 fatty acids and in dietary fat at $40 \%$ of total energy intake, including a high intake of olive oil and special high monounsaturated spread. The Lyon diet was also high in fruits, vegetables, and whole grains and emphasized legumes and fish. The study's conclusions reported that people adhering to a Mediterranean-style diet demonstrated up to $70 \%$ lower death rates compared to those following a low-fat diet. The protective effects of the diet began to occur within two months of observation. In fact, the efficacious results of the Lyon Diet Heart Study were not seen with other diets, drugs, or medical procedures [19].

\subsubsection{The PREDIMED Study}

The PREDIMED study recruited men (55 to 80 years of age) and women (60 to 80 years of age) with no history of cardiovascular disease at enrollment, but who were either diagnosed with type 2 diabetes mellitus or who had at least three of the following major risk factors which influence risk for metabolic syndrome development: smoking, hypertension, 
elevated LDL cholesterol levels, low HDL cholesterol levels, overweight or obesity, or a family history of premature coronary heart disease. Study participants were randomly assigned to one of three dietary intervention groups: (1) Mediterranean diet supplemented with extra-virgin olive oil (approximately 1 liter per week); (2) Mediterranean diet supplemented with $\sim 30 \mathrm{~g}$ of mixed nuts per day; (3) control low-fat diet. No total calorie restriction was advised, nor was physical activity promoted. The study concluded that among persons at high cardiovascular risk, a Mediterranean-style diet supplemented with extra-virgin olive oil or nuts reduced the incidence of major cardiovascular events, compared to the control diet [20].

\subsection{Longevity}

There have been many large prospective observational studies which confirm the benefits of adopting a Mediterranean diet on longevity. In a six-year study evaluating diet composition and quality, researchers found that people who live in Greece and consume a traditional Mediterranean-style diet have much lower rates of mortality than Greeks who have emigrated and adopted Western-style dietary practices [21]. The researchers categorized the traditional Greek diet into four separate components based upon consumption patterns: low consumption of red meat, high consumption of grains, high consumption of vegetables, and moderate consumption of wine. Each component was assigned a "diet score". The study discovered that for each additional dietary component included in a person's diet, the risk of mortality dropped by $17 \%$. The study leader Dr. Dimitrios Trichopoulos from Harvard School of Public Health stated: "Fruits and vegetables help prevent cancer and heart disease, and that modest amounts of wine are cardio-protective, now we know that the overall dietary pattern-rather than individual components-is important for health and longevity. Mediterranean diet is a diet you can easily introduce or use even in the American diet because it does not require sacrifice" [21].

A similar study conducted in Melbourne, Australia, by the same research group found similar results as the Harvard study, thus indicating that a diet which adheres to the principles of the traditional Mediterranean diet is positively associated with longer rates of survival among individuals of either Greek or Anglo-Celtic origin [22].

The HALE study, "The Healthy Ageing: A Longitudinal study in Europe", observed healthy elderly men and women aged 70-90. The results again prescribed the notion that following a Mediterranean diet, in combination with a healthful lifestyle, is associated with more than 50\% lower rates of all-cause and cause-specific mortality [23].

\subsection{Cancer}

In a follow-up report on the Lyon Diet Heart Study, it was also discovered that cancer rates among the Mediterranean-style diet group were $61 \%$ lower than those on the Westernstyle diet. In the Greek European Prospective Investigation into Cancer and Nutrition (EPIC), a cohort with over 25,000 participants, a 12\% reduction in cancer incidence was observed in those who adhered to a traditional Mediterranean diet to a greater degree [24].

A literature review analyzing previous studies on the Mediterranean diet demonstrated how strictly following a Mediterranean-style diet is associated with reduced risk of death from cancer and cardiovascular disease by $9 \%$ and $6 \%$, as well as the risk of developing Parkinson's and Alzheimer's disease by 13\% [25].

\subsection{Metabolic Syndrome and Type 2 Diabetes Mellitus}

A meta-analysis of 50 original research studies ( 35 clinical trials, 2 prospective, and 13 cross-sectional), with over half a million participants, assessed the effect of a Mediterranean diet on metabolic syndrome (MS) as well as its associated conditions. Metabolic syndrome (MS), an important global issue, is characterized by a cluster of physiological abnormalities including abdominal obesity, raised fasting plasma glucose, high levels of total cholesterol and triglycerides, as well as high blood pressure, a state of low-grade chronic immune activation. It is also a major risk factor for cardiovascular disease and type 
2 diabetes. According to this extensive analysis, following a Mediterranean dietary pattern is associated with lower MS prevalence and progression. Furthermore, greater adherence to this traditional dietary pattern is associated with favorable and reverse effects of the MS conditions [26]. Furthermore, in 2008, a prospective study of more than 13,000 people confirmed anew that those with greater adherence to a traditional Mediterranean diet were $83 \%$ less likely to develop type 2 diabetes mellitus [27].

It is important to note that the Mediterranean-style dietary pattern in studies is not homogeneous. However, all of the studies included share the basic, core characteristics of the diet: high consumption of monounsaturated fatty acids; daily consumption of fruits, vegetables, whole grain cereals, weekly consumption of fish, poultry, tree nuts, and legumes; a relatively low consumption of red meat, approximately twice/month; and moderate daily consumption of alcohol, normally with meals.

\section{Mediterranean Diet Effect on Cognitive Function}

High intake of monounsaturated fats, wine, and grains was associated with less cognitive decline. Higher adherence to a Mediterranean diet was associated with $28 \%$ less risk of developing mild cognitive impairment in older Americans, and $40 \%$ less risk for developing Alzheimer's. A meta-analysis comprising 1.5 million subjects from 3 continents concluded that greater adherence to a Mediterranean diet determines 13\% reductions in incidence of Parkinson's and Alzheimer's disease [28].

\subsection{Brain Morphology and Function}

Several studies have suggested that long-term adherence to the MD is associated with preserved white matter microstructure, less cortical thinning in the brain, and better connectivity in the hippocampus and is therefore related to improved sporadic memory, executive function, and global cognition [29-32]. Neuroimaging has been heavily relied upon to make this argument by many studies, including the North Manhattan Study, which reported a beneficial impact of the MD adherence on white matter areas of high intensity revealed via magnetic resonance imaging (MRI) brain scans [31,33]. There are many proposed mechanisms for which the MD promotes cerebrovascular health: through improvement of $\beta$-amyloid plaque clearance in the brain [28,31]; by decreased oxidative stress and inflammation, as well as improved insulin sensitivity [29,34-37]; by reduced intake of saturated fatty acids, trans fatty acids, and conjugated linoleic acid that are prevalent in most meat products [38-40]; and by increased intake of omega-3 fatty acids abundant in fish and eggs [38].

Independent neuroimaging research has found that higher fish intake and lower meat intake were linked with higher total brain, gray matter, and white matter volume. By contrast, Titova et al. found no association between meat intake and brain volume but did discover a positive relationship between EPA and DHA intake and greater gray matter volume $[38,41]$. Conversely, Samieri et al. concluded that higher plasma EPA, but not DHA, was related to lower gray matter atrophy in the right hippocampal area [29,42]. Independent research suggests that the individual foods or nutrients comprising the MD do contribute to the enhancement of global cognition observed; however, further research is necessary to determine the significance of the pattern as a whole. Scarmeas et al. determined that the MD was associated with reduced brain infarcts (i.e., death of brain tissue) [41,43]. Current discourse remains regarding the mechanism by which enhanced cognitive performance is observed.

\subsection{Alzheimer's Disease and Dementia}

The MD has also been associated with lower risk of Alzheimer's disease. In a study by Columbia University's Taub Institute for Research in Alzheimer's Disease and The Aging Brain, researchers conducted a prospective study that followed participants every 1.5 years over up to 7 years. A total of 2258 individuals from 3 geographically defined areas of Manhattan, New York, were recruited, and MD adherence was assessed based 
on a scale of 0-9. Then, 12 tests encompassed in a "neuropsychological battery" were administered in which memory, orientation, abstract reasoning, language, and construction were assessed. The results demonstrated that higher adherence to the MD was associated with a significant reduction in risk for Alzheimer's disease. Indeed, each additional point on the MD score was associated with $9 \%$ to $10 \%$ risk reduction for AD development. The participants in the lowest tertile for MD score saw the greatest risk for development of $\mathrm{AD}$, while the middle tertile had a $15 \%$ to $21 \%$ lower risk and the highest tertile group (highest adherence to MD) saw up to $40 \%$ risk reduction for AD onset compared to the group with the lowest reported MD adherence. This study is one of many to suggest a possible dose-response effect of MD adherence on risk for AD and rate of cognitive decline. Variables which should be considered in the causal relationship between the MD and AD include the following physiological effects of high MD adherence: reduced inflammatory and coagulation markers, including white blood cell counts and fibrinogen; reduced homocysteine levels; and lower CRP and interleukin-6 serum levels [44].

\subsection{Aging and Senescence}

Congruently with the onset of dementia and Alzheimer's, the MD has been found to provide greater benefits to the elderly and aging communities. In Barcelona, Spain, a clinical trial was conducted assessing the impact of antioxidant-rich foods in the MD on asymptomatic older (age 55-80 y) adults with increased risk of cardiovascular disease. Food intake, urinary polyphenols, cardiovascular risk profile, apolipoprotein E genotype, and neuropsychological tests were used to evaluate cognitive function and lead to conclusions regarding the individual cognitive impact of specific foods. Total olive oil intake was associated with immediate verbal memory, coffee ingestion with delayed verbal memory, walnuts with working memory, wine with elevated mini-mental state examination scores, and urinary polyphenols with immediate verbal memory. The greatest impact was seen in increased antioxidant consumption, especially polyphenols, which was associated with better cognitive performance in elderly individuals at elevated cardiovascular risk [45]. Furthermore, many clinical studies have shown that when animals are fed antioxidantrich foods, they exhibit improved cellular signaling and neuronal communication, which translates into better cognitive and motor performance. Neurodegenerative diseases are characterized by a chronic inflammatory state, enhanced by oxidative stress; therefore, the MD favorably counteracts the inevitable decline in brain function as a natural consequence of senescence [45].

\section{Key Components of the Mediterranean Diet}

The antioxidant and anti-inflammatory effects of the MD as a whole, as well as the effects of the individual components of the MD and specifically in olive oil, fruits and vegetables, whole grains, and fish, could explain, at least partially, the beneficial findings on physical health and wellbeing.

\subsection{Olive Oil}

The MD is known for its emphasis on olive oil consumption, and specifically its concentration of monounsaturated fats (MUFA) at 77\%. MUFA are less prone to oxidation than trans or polyunsaturated fatty acids due to their chemical structure, where only one double bond is considered susceptible to free radical damage, thus rendering them less prone to oxidation. Olive oil is also high in antioxidant content, including tocopherol, hydroxytyrosol, and oleuropein, high in sterols which help to reduce LDL and increase HDL, and can favorably affect gene expression related to atherosclerosis development [46].

\subsection{Fish}

Fish is another key foodstuff consumed as part of the traditional MD. Fish meat is high in very long chain omega-3 fatty acids, namely, anti-inflammatory EPA and DHA, which have been shown to decrease risk of cardiac death by $30-45 \%$ [47]. Fish meat is 
also less prone to pro-inflammatory cytokine conversion upon digestion compared to red meat, largely due to the difference in lipid composition [48]. Finally, fish consumption has been shown to induce a $43 \%$ increase in nitric oxide, which promotes vaso-relaxation [46]. Via these physiological responses, regular consumption of fish lowers the risk of fatal myocardial infarction. In addition, several human studies have confirmed that along with olive oil, it may also modify inflammatory cytokine production and potentially decrease the severity of autoimmune disorders. Finally, olive oil and possibly omega-3 fatty acids may also possess non-steroid anti-inflammatory drug-like activity, similar to that of aspirin [49].

In the epidemiological Cardio2000 study, fish consumption of about $150 \mathrm{~g}$ per week was associated with $38 \%$ lower odds of developing acute coronary syndrome compared to no consumption [50]. Another study by London et al. found an overall mortality reduction of $29 \%$ in survivors of a first myocardial infarction in those who consumed omega-3 rich fish at least twice a week [51]. The health benefits of fish consumption are consistently portrayed to be strong. Of note, the benefits of fish consumption exceed the potential risks of heavy metal exposure.

\subsection{Nuts}

Nuts are another key component of the MD pattern and accompanying health benefits. High in polyunsaturated or monounsaturated fats, low in saturated fats, high in fiber, and high in omega-3s, the nutritional advantages of nuts are commonly overlooked. Specifically, omega-3s function to affect cell proliferation, survival, angiogenesis, and inflammation to subsequently slow cancer progression and metastasis [52,53]. Almonds, pumpkin seeds, and walnuts, in particular, are very high in omega-3 fatty acids [52]. Sabaté and colleagues found that the addition of walnuts into a MD, as opposed to their exclusion, resulted in a significant reduction in LDL [54]. In another study of two large, independent cohorts of nurses (76,464 women) and other health professionals (42,498 men) [55], the frequency of nut consumption was inversely associated with total and cause-specific mortality, independently of other predictors of death. This foregoing evidence further supports the argument that each individual component of the MD is essential to the collective pattern that yields the observed health benefits [55].

\subsection{Vegetables and Fruit}

In addition to vitamins, minerals, and water, the considerable amount and variety of plant foods in the Mediterranean diet also contribute a large proportion of the overall dietary fiber and phytonutrient intake. Fiber is essential to bowel health, while helping to increase satiety after a meal and delay hunger. Most vegetables largely confer insoluble fiber, while fruits are host to soluble fiber $[56,57]$. Both kinds are crucial in the development and fostering of a healthy gut microbiome. Insoluble fiber primarily serves as a bulking agent in fecal matter as well as a source for fermentation by colonic bacteria; the result is a minute quantity of short-chain fatty acids. Insoluble fiber is attributed to the blockage of LPS translocation, attributed to endotoxemia. Conversely, soluble fiber is responsible for the production of a large quantity of short-chain fatty acid metabolites and induces the proliferation of beneficial bacteria in the gut. Among the bacteria in the gut, Prevotella are one genus of particular significance. Prevotella proliferation has been shown to have a direct correlation with fruit/vegetable intake. In addition, vegans and vegetarians, who tend to consume more plant foods, typically see a greater abundance of Bacteroidetes and a lower overall Firmicutes: Bacteroidetes ratio compared to omnivores. Firmicutes specifically help in the digestion of carbohydrates not naturally digested by an individual and subsequently reduce overall stress within the host $[56,58]$.

Additional beneficial properties in fruits and vegetables include phytonutrients, which are usually color-rich substances synthesized by plants for protection in response to environmental stress, such as heat, drought, pests, acidic soils. When a variety of these phytonutrients (phenolics, flavonoids, anthocyanins) are consumed by humans, they offer protection against oxidative stress and inflammation and thereby hold potential in prevent- 
ing/delaying chronic degenerative diseases and associated abnormalities [59]. Polyphenols are one class of phytonutrients that are of particular importance. Abundant in acidic fruits and vegetables, these compounds are valued for their antioxidant capacity and chemical nature. Their unique structure allows them to accept and stabilize free-floating electrons in order to prevent a subsequent oxidation reaction in the body [52,56]. For this reason, they are said to have a protective capacity. Another fundamental phytonutrient is phytosterols, distinct from other nutrients for their ability to control the intestinal absorption of cholesterol [52]. The cumulative effects of the many phytonutrients only broadly defined here are best obtained from the consumption of a diet rich in a variety of fruits and vegetables and are crucial in the defense against pathology.

\subsection{Legumes and Beans}

Legumes and beans constitute a staple source of nutrition in the traditional Mediterranean diet, especially when considering that meat is usually consumed infrequently. Both provide significant protein, fiber, iron, and B vitamins in the diet. Among the most abundant nutrients in legumes is fiber. Fiber is associated with a reduction in insulin resistance, the inhibition of intentional absorption of cholesterol, and the inhibition of hepatic cholesterol synthesis [52]. Specifically, the regular consumption of chickpeas has been proven to lower LDL cholesterol and decrease fasting insulin [60-63]. For these reasons, among others, increased legume consumption is associated with decreased coronary heart disease [61-63]. Their dense fiber content is also significant in the effect of MD on cancer, specifically of prostate and gastric origin. High-fiber diets have been commonly associated with lower rates of carcinogenesis due to the reduction of time the food bolus spends in the digestive tract, as well as the resultant overall decreased inflammation.

\subsection{Herbs and Spices}

Herbs and spices grown in the mountainous and coastal regions in the Mediterranean area are a key ingredient in the unique flavor of many Mediterranean dishes, while many herbs and spices have been shown to extend potential health benefits [64]. Including but not limited to cumin, parsley, oregano, rosemary, thyme, and sage, herbs and spices are crucial to the unique flavor profile of the MD [65]. In addition to offering an abundance of phytochemicals such as flavonoids, anthocyanins, isoflavones, terpenes, and isothiocyanates, they also play essential roles as antioxidant and anti-inflammatory agents, improving insulin sensitivity, counteracting dyslipidemia, and slowing down effects of the aging process [66]. Additionally, the high antioxidant content of the spices so ubiquitous in traditional Mediterranean cooking is used to enhance the taste and freshness of olive oil. Moreover, the fact that a plethora of herbs and spices are used in the Mediterranean diet renders the food typically tasteful, thus likely reducing the possibility for overeating. Furthermore, less salt may be used as a result of the use of other spices that confer flavor, thus reducing the excessive intake of sodium through the diet.

\subsection{Wine}

The craft of wine, or "oenos" (from Greek: oivos), for "the benevolent demon" as termed by Ancient Greek gastronomist and philosopher Athinaios, plays a great sociocultural role in the Mediterranean region [67]. In addition, it has demonstrated immense effects on health when consumed in moderation; recommended daily intake is 2 glasses for men $/ 1$ for women $(1$ glass $=150 \mathrm{~mL}$ ). Wine is very rich in phytochemicals (similar to fruits and olive oil) and specifically through its high polyphenolic content is believed to counteract oxidative stress and provide antiatherogenic properties [68]. Known as the "French Paradox", the consumption of wine has been associated with a noticeably low prevalence of ischemic heart disease, regardless of saturated fat intake. Significant debate exists among epidemiological investigators as to whether this benefit can be attributed to wine specifically, or if it pertains to beers and spirits as well. However, the data seem 
to be stronger for red wine as opposed to other alcoholic beverages. Further research is necessary to reach such a conclusion [68].

\section{Prevalent Dietary Scheme Contrast}

While the MD falls into its own unique category of dietary and lifestyle choices, it is often compared alongside vegetarian, pescatarian, and vegan diets due to their similar natures. Here, we compare the MD alongside four other dietary schemes: a ketogenic-like diet, an Atkins-like diet, the Paleo diet, and the DASH diet. Coinciding with many of these diets, the MD has also been associated with weight loss benefits. Repeatedly, long-term MD adherence in overweight and obese individuals has resulted in sustained weight loss. Specifically, in 2008, Shai et al. [69] conducted a two-year randomized control trial in which moderately obese individuals were assigned to either a low-fat, low carbohydrate (LC), or MD. Researchers discovered that despite enforcing caloric restriction among only the MD group, the LC individuals consumed a more hypocaloric diet on average. Additionally, MD individuals saw a better sustained weight loss compared with LC individuals, who saw a more drastic decline followed by fluctuations. Finally, at the end of the two-year trial, MD and LC individuals saw very similar weight loss values, $-4.4 \pm 6.0 \mathrm{~kg}$ and $-4.7 \pm 6.5 \mathrm{~kg}$, respectively. While the role of MD along with those of ketogenic, Atkins, and Paleo diets have all proven to provoke weight loss, the most significant, and likely coinciding, application of such regimens is in their role in evading entirely or combating chronic disease.

\subsection{A Ketogenic-Like Diet}

The "Keto-diet" (ketogenic diet, KD) is characterized by a high-fat, low-carbohydrate intake. Cumulatively, the production of ketone bodies (i.e., acetoacetate, $\beta$-Hydroxybutyrate, acetone) and glucose restriction leads to a shift in the primary fuel source of the body, resulting in unique interactions with receptors, channels, and metabolic enzymes [70,71]. Ketogenic dietary schemes have gained popularity as a treatment form, and in some cases, a medication-replacement for type 2 diabetes mellitus [71-74]. Unlike the MD, the KD consists of mostly long-chain saturated triglycerides [70]. The mechanism by which the KD improves glycemic control in T2DM is believed to be through (1) initiating an energy shift from glucose to fat, in the form of ketone bodies, leading to fat loss and a reduced need for insulin production and (2) making it simpler to control blood sugar spikes and hypoglycemia [73-75]. Low-carbohydrate diets and specifically the KD have gained popularity in the last decade. However, while such diets are effective, growing evidence suggests caution must be exercised if an individual is of young age, with a pathologic condition, and/or is following the diet for long periods of time [75]. Additionally, it is worth noting that a strict KD regimen restricts not only carbohydrate intake, but also protein, therefore potentiating renal, bone, and lean tissue mass damage, among other consequences.

\subsection{The Atkins Diet}

The Atkins diet seemingly mimics the ketogenic diet but allows for increased leniency in protein consumption and carbohydrate intake, requiring restriction of carbohydrate at under $30 \mathrm{~g} /$ day. The Atkins diet advocates for a high percentage of fat intake, no restriction of protein intake, and low-carbohydrate intake. Similar to that of the ketogenic diet, the objective is to induce a shift in the primary energy source from glucose to fat, through the hepatic production of ketone bodies [74,75].

Unlike the MD, the Atkins diet allows for ad libitum intake of fatty meat, butter, and other high fat dairy products. Nonetheless, following the Atkins diet has been shown to promote weight loss and improve glycemic control in individuals with type 2 diabetes mellitus [74]. In a systematic review of two longer-term randomized control trials, comparing a low-carbohydrate diet and a low-fat, calorie-reduced diet, both trials demonstrated significant weight loss on the low-carbohydrate diet after 6 months, but no difference after 12 months [75]. The low-carbohydrate weight loss paradox that currently prevails 
in pop culture is severely lacking in that knowledge of the long-term effects is minimal. Astrup et al., in Copenhagen, Denmark, produced research showing that following a diet of ketogenic nature may promote weight loss via the depletion of glycogen stores, leading to the excretion of bound water, and appetite suppression by the highly satiating nature of a high-protein diet. The long-term effects of this diet scheme are needed to measure: "changes in nutritional status and body composition during the low-carbohydrate diet, and to assess fasting and postprandial risk factors and adverse effects. Without that information, low carbohydrate diets cannot be recommended" [74].

\subsection{The Paleo Diet}

The Paleo diet received its name due to its similar nature as consumed during the Paleolithic era. It has also gained esteem for weight loss, diabetes management, and general wellbeing. While no standard definition exists, the diet recommends avoidance of processed foods, refined sugars, legumes, daily, grains, and cereals and instead advocates for grass-fed meat, wild fish, fruits, vegetables, and nuts [76]. Deemed a high-protein, low-fat diet, the diet is focused on fresh foods and the avoidance of processed foods $[76,77]$. The greatest divide existing between the MD and the Paleo diet is the recommendation of grains and cereal consumption. The MD emphasizes the potential health benefits which may result from increased fiber intake alongside other features of the diet, while the Paleo diet recommends its fiber avoidance due to the practically inevitable amount of added sugar likely to coexist in the contemporary dietary scene [76,77].

Despite the popularity of this diet, the literature is very limited, and clinical studies are sparse. In one randomized crossover study of a 3-month Paleolithic diet compared with the standard diet recommended to type 2 diabetic patients, Lindeberg et al. found that the Paleolithic diet achieved a significantly lower BMI and HbA1c value, as well as higher HDL and triglyceride levels, and lower diastolic pressure [78]. Further clinical trials are necessary to confirm the observed effects of this study. Additionally, future studies should examine long-term adherence and motivation to comply.

\subsection{The Nordic Diet}

Often compared for its similarities to the MD, the Nordic diet has roots across Northern Europe (Denmark, Sweden, Finland). Characterized by its emphasis on the consumption of healthy regional-specific foods, like the MD, the Nordic diet is dominated by apples, pears, berries, root and cruciferous vegetables, cabbages, and whole grain and rye bread, as well as a high intake of fish, low-fat dairy products, potatoes, and vegetable fats, among other dietary lipid sources [79]. Very little research has been conducted thus far regarding the long-term effects of adherence to a Nordic diet. Nonetheless, in a study conducted by the German Institute of Human Nutrition Potsdam-Rehbrüecke, a non-significant inverse association was determined for incidence of myocardial infarctions overall and of stroke in men [79]. No association was determined with incidence of type 2 diabetes, thus further intensifying the interest among researchers into what components of the MD provide the observed cardioprotective effect.

\subsection{The DASH Diet}

Finally, the Dietary Approach to Stop Hypertension (DASH) has grown immensely popular and is now recommended in natural guidelines in the United States, due to the rise in obesity, T2DM, and hypertension, which comprise a major public health concern. The DASH diet recommends a diet rich in vegetables and fruits and low-fat dairy products and includes whole grains, poultry, fish, and nuts and allows only a small amount of meat, sweets, and sugar-containing beverages [80]. Unlike the MD, the DASH diet emphasizes decreased amounts of total/saturated fat and cholesterol due to its ultimate purpose, which is to limit sodium intake and subsequently reduce systolic and diastolic blood pressure [80].

Also, worth noting is the association between the Mediterranean diet, DASH diet, and Alzheimer's disease, cumulatively known as the MIND diet (the Mediterranean-DASH 
Intervention associated to reduced incidence of Alzheimer's disease) [81]. In another study, a food frequency questionnaire was utilized to determine that among 923 participants, followed every 4.5 years, a greater adherence to the MIND diet proved to be as effective as, if not more than, the DASH diet or MD alone [81]. They concluded that individuals in the highest tertile of MIND adherence saw a 53\% reduction in rate of $A D$, while the middle tertile of scores saw a 35\% reduction compared with the lowest tertile [81].

Regardless of the type of diet compared alongside, the Mediterranean diet is a paradigm being reintroduced to the global food scene as a healthy lifestyle practice that can promote sustainable public health and prevention against noncommunicable diseases such as obesity, cancer, type 2 diabetes mellitus, and cardiovascular disease. Collectively, these diseases constitute the main cause of death globally and pose a tremendous financial burden on healthcare systems [82]. In line with the UNESCO definition and view on the Mediterranean diet, ways to adopt the principles and adapt the dietary approach according to the needs of the populations and individuals need to be investigated. As the Mediterranean diet allows for flexibility due to its innate diversity, it can be used as the foundation for a plant-based personalized nutrition approach across the lifespan. Notably, the health benefits of the Mediterranean diet constitute a sustainable approach in food systems as the diet primarily promotes the consumption of plant foods which are locally and seasonally produced.

\section{Conclusions}

The whole collective MD is superior to the sum of its individual component parts, for it is their interactions and associations which produce the aforementioned health benefits. Important characteristics of the Mediterranean diet as a whole are a low glycemic index due to the bulk of diet and a high satiating effect, which prevents overeating and the sense of being on a diet. The results of the research on the health effect of the Mediterranean diet are of considerable public health importance, because this dietary pattern can be easily adopted by all population groups of various cultures, and cost-effectively serve as primary and secondary prevention measures for cardiovascular disease, metabolic syndrome, and cancer. The incidence of non-communicable diseases has drastically increased in recent years and is very unlikely to decrease unless drastic measures are applied. In spite of efforts to promote a healthy lifestyle and encourage a healthier diet and increase physical activity, dietary habits in the developed world and in some developing countries are changing toward the opposite direction. Even around the Mediterranean basin, consumption of fat, meat, eggs, dairy products, and sugar has increased, and consumption of cereals, legumes, vegetables, and seafood has decreased.

Author Contributions: A.K.S. and A.S.K. conceived and conceptualized the idea. A.H.K. contributed to the literature search review and organization of resources. A.K.S. wrote the initial manuscript. A.S.K. revised the manuscript. All authors have read and agreed to the published version of the manuscript.

Funding: This research received no external funding.

Acknowledgments: The authors would like to thank the Consulate General of Greece in Istanbul and the Sismanogleio Megaro, with special thanks to their excellences Ambassador Nikolaos Matthioudakis and Consul General Victor Maligoudis, for extending their kind invitation to Kristo and Sikalidis, to present the topic of the Mediterranean diet in a special educational invited talk in 2014. That event sparked the idea for the current entry herein, upon invitation by MDPI.

Conflicts of Interest: The authors declare no conflict of interest.

Entry Link on the Encyclopedia Platform: https:/ / encyclopedia.pub/927.

\section{References}

1. Willett, W.C.; Sacks, F.; Trichopoulou, A.; Drescher, G.; Ferro-Luzzi, A.; Helsing, E.; Trichopoulos, D. Mediterranean diet pyramid: A cultural model for healthy eating. Am. J. Clin. Nutr. 1995, 61, 1402S-1406S. [CrossRef]

2. Nestle, M. Mediterranean diets: Historical and research overview. Am. J. Clin. Nutr. 1995, 61, 1313S-1320S. [CrossRef] [PubMed] 
3. Haber, B. The Mediterranean diet: A view from history. Am. J. Clin. Nutr. 1997, 66, 1053S-1057S. [CrossRef] [PubMed]

4. Helsing, E. Traditional diets and disease patterns of the Mediterranean, circa 1960. Am. J. Clin. Nutr. 1995, 61, 1329S-1337S. [CrossRef]

5. U.S. Department of Agriculture; U.S. Department of Health and Human Services. Dietary Guidelines for Americans, 2020-2025, 9th ed. Available online: https:/ / dietaryguidelines.gov (accessed on 13 December 2020).

6. The Odyssey; Translated by Robert Fitzgerald; Everyman's Library: New York, NY, USA, 1992.

7. Hesiod. Theogony, Works and Days; Testimonia Loeb Classical Library: Cambridge, MA, USA, 2006; p. 119.

8. Skiadas, P.K.; Lascaratos, J.G. Dietetics in ancient Greek philosophy: Plato's concepts of healthy diet. Eur. J. Clin. Nutr. 2001, 55, 532-537. [CrossRef]

9. Minelli, P.; Montinari, M.R. The Mediterranean Diet and Cardioprotection: Historical Overview and Current Research. J. Multidiscip. Health 2019, 12, 805-815. [CrossRef]

10. Conti, A.A.; Lippi, D.; Gensini, G.F. Obesity and nutritional behavior within a historical perspective. Minerva Gastroenterol. Dietol. 2004, 50, 171-177. [PubMed]

11. Trichopoulou, A. Mediterranean diet: The past and the present. Nutr. Metab. Cardiovasc. Dis. 2001, 11, 1-4. [PubMed]

12. Aboul-Enein, B.H.; Puddy, W.C.; Bernstein, J. Ancel Benjamin Keys (1904-2004): His early works and the legacy of the modern Mediterranean diet. J. Med Biogr. 2020, 28, 139-147. [CrossRef]

13. Simopoulos, A.P. The Mediterranean Diets: What Is So Special about the Diet of Greece? The Scientific Evidence. J. Nutr. 2001, 131, 3065S-3073S. [CrossRef]

14. The American Heritage Dictionary of the English Language, 4th ed.; Houghton Mifflin: Boston, MA, USA, 2000.

15. UNESCO. Intangible Cultural Heritage. Available online: https://ich.unesco.org/en/RL/mediterranean-diet-00884 (accessed on 12 February 2021).

16. The Mediterranean Diet Pyramid. Available online: https://oldwayspt.org/resources/oldways-mediterranean-diet-pyramid (accessed on 12 February 2021).

17. Menotti, A.; Puddu, P. How the Seven Countries Study contributed to the definition and development of the Mediterranean diet concept: A 50-year journey. Nutr. Metab. Cardiovasc. Dis. 2015, 25, 245-252. [CrossRef]

18. Keys, A.B. Seven Countries: A Multivariate Analysis of Death and Coronary Heart Disease; Ancel, K., Ed.; Harvard University Press: Cambridge, MA, USA, 1980; ISBN 0-674-80237-3.

19. De Lorgeril, M.; Salen, P.; Martin, J.-L.; Monjaud, I.; Delaye, J.; Mamelle, N. Mediterranean Diet, Traditional Risk Factors, and the Rate of Cardiovascular Complications After Myocardial Infarction. Circulation 1999, 99, 779-785. [CrossRef]

20. Estruch, R.; Ros, E.; Salas-Salvadó, J.; Covas, M.-I.; Corella, D.; Arós, F.; Gómez-Gracia, E.; Ruiz-Gutiérrez, V.; Fiol, M.; Lapetra, J.; et al. Primary Prevention of Cardiovascular Disease with a Mediterranean Diet Supplemented with Extra-Virgin Olive Oil or Nuts. N. Engl. J. Med. 2018, 378, e34. [CrossRef] [PubMed]

21. Trichopoulos, D. In defense of the Mediterranean diet. Eur. J. Clin. Nutr. 2002, 56, 928-929. [CrossRef] [PubMed]

22. Kouris-Blazos, A.; Gnardellis, C.; Wahlqvist, M.L.; Trichopoulos, D.; Lukito, W.; Trichopoulou, A. Are the advantages of the Mediterranean diet transferable to other populations? A cohort study in Melbourne, Australia. Br. J. Nutr. 1999, 82, 57-61. [CrossRef]

23. Knoops, K.T.; de Groot, L.C.; Kromhout, D.; Perrin, A.E.; Moreiras-Varela, O.; Menotti, A.; van Staveren, W.A. Mediterranean diet, lifestyle factors, and 10-year mortality in elderly European men and women: The HALE project. JAMA 2004, 292, 1433-1439. [CrossRef] [PubMed]

24. Bradbury, K.E.; Appleby, P.N.; Key, T.J. Fruit, vegetable, and fiber intake in relation to cancer risk: Findings from the European Prospective Investigation into Cancer and Nutrition (EPIC). Am. J. Clin. Nutr. 2014, 100, 394S-398S. [CrossRef] [PubMed]

25. Sofi, F.; Cesari, F.; Abbate, R.; Gensini, G.F.; Casini, A. Adherence to Mediterranean diet and health status: Meta-analysis. BMJ 2008, 337, a1344. [CrossRef]

26. Kastorini, C.-M.; Milionis, H.J.; Esposito, K.; Giugliano, D.; Goudevenos, J.A.; Panagiotakos, D.B. The Effect of Mediterranean Diet on Metabolic Syndrome and its Components. J. Am. Coll. Cardiol. 2011, 57, 1299-1313. [CrossRef] [PubMed]

27. Martínez-González, M.Á.; De La Fuente-Arrillaga, C.; Nunez-Cordoba, J.M.; Basterra-Gortari, F.J.; Beunza, J.J.; Vazquez, Z.; Benito, S.; Tortosa, A.; Bes-Rastrollo, M. Adherence to Mediterranean diet and risk of developing diabetes: Prospective cohort study. BMJ 2008, 336, 1348-1351. [CrossRef]

28. Panza, F.; Solfrizzi, V.; Colacicco, A.M.; D’Introno, A.; Capurso, C.; Torres, F.; Del Parigi, A.; Capurso, S.; Capurso, A. Mediterranean diet and cognitive decline. Public Health Nutr. 2004, 7, 959-963. [CrossRef] [PubMed]

29. Masana, M.F.; Koyanagi, A.; Haro, J.M.; Tyrovolas, S. n-3 Fatty acids, Mediterranean diet and cognitive function in normal aging: A systematic review. Exp. Gerontol. 2017, 91, 39-50. [CrossRef] [PubMed]

30. Mosconi, L.; Murray, J.; Tsui, W.H.; Li, Y.; Davies, M.; Williams, S.; Pirraglia, E.; Spector, N.; Osorio, R.S.; Glodzik, L.; et al Mediterranean Diet and Magnetic Resonance Imaging-Assessed Brain Atrophy in Cognitively Normal Individuals at Risk for Alzheimer's Disease. J. Prev. Alzheimer's Dis. 2014, 1, 23-32.

31. Loughrey, D.G.; Lavecchia, S.; Brennan, S.; Lawlor, B.A.; Kelly, M.E. The Impact of the Mediterranean Diet on the Cognitive Functioning of Healthy Older Adults: A Systematic Review and Meta-Analysis. Adv. Nutr. 2017, 8, 571-586. [CrossRef] 
32. Pelletier, A.; Barul, C.; Féart, C.; Helmer, C.; Bernard, C.; Periot, O.; Dilharreguy, B.; Dartigues, J.-F.; Allard, M.; Barberger-Gateau, P.; et al. Mediterranean diet and preserved brain structural connectivity in older subjects. Alzheimer's Dement. 2015, 11, 1023-1031. [CrossRef]

33. Gardener, H. Mediterranean Diet and White Matter Hyperintensity Volume in the Northern Manhattan Study. Arch. Neurol. 2012, 69, 251-256. [CrossRef]

34. Ramanathan, A.M.; Nelson, A.R.P.; Sagare, A.P.P.; Zlokovic, B.V.M. Impaired vascular-mediated clearance of brain amyloid beta in Alzheimer's disease: The role, regulation and restoration of LRP. Front. Aging Neurosci. 2015, 7, 136. [CrossRef]

35. Sleiman, D.; Al-Badri, M.R.; Azar, S.T. Effect of Mediterranean Diet in Diabetes Control and Cardiovascular Risk Modification: A Systematic Review. Front. Public Health 2015, 3, 69. [CrossRef]

36. Steele, M.; Stuchbury, G.; Münch, G. The molecular basis of the prevention of Alzheimer's disease through healthy nutrition. Exp. Gerontol. 2007, 42, 28-36. [CrossRef]

37. Tzima, N.; Pitsavos, C.; Panagiotakos, D.B.; Skoumas, J.; Zampelas, A.; Chrysohoou, C.; Stefanadis, C. Mediterranean diet and insulin sensitivity, lipid profile and blood pressure levels, in overweight and obese people; The Attica study. Lipids Health Dis. 2007, 6, 22. [CrossRef]

38. Titova, O.E.; Ax, E.; Brooks, S.J.; Sjögren, P.; Cederholm, T.; Kilander, L.; Kullberg, J.; Larsson, E.-M.; Johansson, L.; Åhlström, H.; et al. Mediterranean diet habits in older individuals: Associations with cognitive functioning and brain volumes. Exp. Gerontol. 2013, 48, 1443-1448. [CrossRef]

39. Granholm, A.-C.; Bimonte-Nelson, H.A.; Moore, A.B.; Nelson, M.E.; Freeman, L.R.; Sambamurti, K. Effects of a Saturated Fat and High Cholesterol Diet on Memory and Hippocampal Morphology in the Middle-Aged Rat. J. Alzheimer's Dis. 2008, 14, 133-145. [CrossRef] [PubMed]

40. Sartorius, T.; Ketterer, C.; Kullmann, S.; Balzer, M.; Rotermund, C.; Binder, S.; Hallschmid, M.; Machann, J.; Schick, F.; Somoza, V.; et al. Monounsaturated Fatty Acids Prevent the Aversive Effects of Obesity on Locomotion, Brain Activity, and Sleep Behavior. Diabetes 2012, 61, 1669-1679. [CrossRef]

41. Anastasiou, C.A.; Yannakoulia, M.; Kosmidis, M.H.; Dardiotis, E.; Hadjigeorgiou, G.M.; Sakka, P.; Arampatzi, X.; Bougea, A.; Labropoulos, I.; Scarmeas, N. Mediterranean diet and cognitive health: Initial results from the Hellenic Longitudinal Investigation of Ageing and Diet. PLoS ONE 2017, 12, e0182048. [CrossRef]

42. Samieri, C.; Maillard, P.; Crivello, F.; Proust-Lima, C.; Peuchant, E.; Helmer, C.; Amieva, H.; Allard, M.; Dartigues, J.-F.; Cunnane, S.C.; et al. Plasma long-chain omega-3 fatty acids and atrophy of the medial temporal lobe. Neurology 2012, 79, 642-650. [CrossRef]

43. Scarmeas, N.; Luchsinger, J.A.; Stern, Y.; Gu, Y.; He, J.; DeCarli, C.; Brown, T.; Brickman, A.M. Mediterranean diet and magnetic resonance imaging-assessed cerebrovascular disease. Ann. Neurol. 2011, 69, 257-268. [CrossRef] [PubMed]

44. Scarmeas, N.; Stern, Y.; Tang, M.-X.; Mayeux, R.; Luchsinger, J.A. Mediterranean diet and risk for Alzheimer's disease. Ann. Neurol. 2006, 59, 912-921. [CrossRef]

45. Valls-Pedret, C.; Lamuela-Raventós, R.M.; Medina-Remón, A.; Quintana, M.; Corella, D.; Pintó, X.; Martínez-González, M.; Miguel, Á.; Estruch, R.; Ros, E. Polyphenol-Rich Foods in the Mediterranean Diet are Associated with Better Cognitive Function in Elderly Subjects at High Cardiovascular Risk. J. Alzheimer's Dis. 2012, 29, 773-782. [CrossRef] [PubMed]

46. Flori, L.; Donnini, S.; Calderone, V.; Zinnai, A.; Taglieri, I.; Venturi, F.; Testai, L. The Nutraceutical Value of Olive Oil and Its Bioactive Constituents on the Cardiovascular System. Focusing on Main Strategies to Slow Down Its Quality Decay during Production and Storage. Nutrient 2019, 11, 1962. [CrossRef]

47. Kromhout, D.; Yasuda, S.; Geleijnse, J.M.; Shimokawa, H. Fish oil and omega-3 fatty acids in cardiovascular disease: Do they really work? Eur. Heart J. 2011, 33, 436-443. [CrossRef]

48. Balić, A.; Vlašić, D.; Žužul, K.; Marinović, B.; Mokos, Z.B. Omega-3 Versus Omega-6 Polyunsaturated Fatty Acids in the Prevention and Treatment of Inflammatory Skin Diseases. Int. J. Mol. Sci. 2020, 21, 741. [CrossRef]

49. Beauchamp, G.K.; Keast, R.S.J.; Morel, D.; Lin, J.; Pika, J.; Han, Q.; Lee, C.-H.; Smith, A.B.; Breslin, P.A.S. Ibuprofen-like activity in extra-virgin olive oil. Nat. Cell Biol. 2005, 437, 45-46. [CrossRef]

50. Panagiotakos, D.B.; Pitsavos, C.; Stefanadis, C. Dietary patterns: A Mediterranean diet score and its relation to clinical and biological markers of cardiovascular disease risk. Nutr. Metab. Cardiovasc. Dis. 2006, 16, 559-568. [CrossRef] [PubMed]

51. London, B.; Albert, C.; Anderson, M.E.; Giles, W.R.; Van Wagoner, D.R.; Balk, E.; Billman, G.E.; Chung, M.; Lands, W.; Leaf, A.; et al. Omega-3 Fatty Acids and Cardiac Arrhythmias: Prior Studies and Recommendations for Future Research. Circulation 2007, 116, e320-e335. [CrossRef] [PubMed]

52. Mentella, M.C.; Scaldaferri, F.; Ricci, C.; Gasbarrini, A.; Miggiano, G.A.D. Cancer and Mediterranean Diet: A Review. Nutrient 2019, 11, 2059. [CrossRef] [PubMed]

53. Castelló, A.; Boldo, E.; Pérez-Gómez, B.; Lope, V.; Altzibar, J.M.; Martín, V.; Castaño-Vinyals, G.; Guevara, M.; Dierssen-Sotos, T.; Tardón, A.; et al. Adherence to the Western, Prudent and Mediterranean dietary patterns and breast cancer risk: MCC-Spain study. Maturitas 2017, 103, 8-15. [CrossRef] [PubMed]

54. Sabaté, J.; Wien, M. Nuts, blood lipids and cardiovascular disease. Asia Pac. J. Clin. Nutr. 2010, 19, $131-136$.

55. Bao, Y.; Han, J.; Hu, F.B.; Giovannucci, E.L.; Stampfer, M.J.; Willett, W.C.; Fuchs, C.S. Association of Nut Consumption with Total and Cause-Specific Mortality. N. Engl. J. Med. 2013, 369, 2001-2011. [CrossRef]

56. Kelleher, A.H.; Sikalidis, A.K. The Effects of Mediterranean Diet on the Human Gut Microbiota; a Brief Discussion of Evidence in Humans. OBM Hepatol. Gastroenterol. 2021, 5, 1021926-2101056. [CrossRef] 
57. Makki, K.; Deehan, E.C.; Walter, J.; Bäckhed, F. The Impact of Dietary Fiber on Gut Microbiota in Host Health and Disease. Cell Host Microbe 2018, 23, 705-715. [CrossRef]

58. De Filippis, F.; Pellegrini, N.; Vannini, L.; Jeffery, I.B.; La Storia, A.; Laghi, L. High-level adherence to a Mediterranean diet beneficially impacts the gut microbiota and associated metabolome. Gut 2016, 65, 1812-1821. [CrossRef]

59. Aune, D.; Giovannucci, E.; Boffetta, P.; Fadnes, L.T.; Keum, N.; Norat, T.; Greenwood, D.C.; Riboli, E.; Vatten, L.J.; Tonstad, S. Fruit and vegetable intake and the risk of cardiovascular disease, total cancer and all-cause mortality-A systematic review and dose-response meta-analysis of prospective studies. Int. J. Epidemiol. 2017, 46, 1029-1056. [CrossRef]

60. Cory, H.; Passarelli, S.; Szeto, J.; Tamez, M.; Mattei, J. The Role of Polyphenols in Human Health and Food Systems: A Mini-Review. Front. Nutr. 2018, 5, 87. [CrossRef]

61. Duane, W.C. Effects of legume consumption on serum cholesterol, biliary lipids, and sterol metabolism in humans. J. Lipid Res. 1997, 38, 1120-1128. [CrossRef]

62. Ferreira, H.; Vasconcelos, M.; Gil, A.M.; Pinto, E. Benefits of pulse consumption on metabolism and health: A systematic review of randomized controlled trials. Crit. Rev. Food Sci. Nutr. 2021, 61, 85-96. [CrossRef] [PubMed]

63. Bielefeld, D.; Grafenauer, S.; Rangan, A. The Effects of Legume Consumption on Markers of Glycaemic Control in Individuals with and without Diabetes Mellitus: A Systematic Literature Review of Randomised Controlled Trials. Nutrient 2020, 12, 2123. [CrossRef]

64. Jiang, T.A. Health Benefits of Culinary Herbs and Spices. J. AOAC Int. 2019, 102, 395-411. [CrossRef]

65. Vázquez-Fresno, R.; Rosana, A.R.R.; Sajed, T.; Onookome-Okome, T.; Wishart, N.A.; Wishart, D.S. Herbs and Spices-Biomarkers of Intake Based on Human Intervention Studies-A Systematic Review. Genes Nutr. 2019, 14, 1-27. [CrossRef] [PubMed]

66. Lampe, J.W. Spicing up a vegetarian diet: Chemopreventive effects of phytochemicals. Am. J. Clin. Nutr. 2003, 78, 579S-583S. [CrossRef] [PubMed]

67. Maykish, A.; Rex, R.; Sikalidis, A.K. Organic Winemaking and Its Subsets; Biodynamic, Natural, and Clean Wine in California. Foods 2021, 10, 127. [CrossRef]

68. Artero, A.; Artero, A.; Tarín, J.J.; Cano, A. The impact of moderate wine consumption on health. Maturitas 2015, 80, 3-13. [CrossRef] [PubMed]

69. Shai, I.; Schwarzfuchs, D.; Henkin, Y.; Shahar, D.R.; Witkow, S.; Greenberg, I.; Golan, R.; Fraser, D.; Bolotin, A.; Vardi, H.; et al. Weight Loss with a Low-Carbohydrate, Mediterranean, or Low-Fat Diet. N. Engl. J. Med. 2008, 359, 229-241. [CrossRef] [PubMed]

70. Boison, D. New insights into the mechanisms of the ketogenic diet. Curr. Opin. Neurol. 2017, 30, 187-192. [CrossRef] [PubMed]

71. Bolla, A.M.; Caretto, A.; Laurenzi, A.; Scavini, M.; Piemonti, L. Low-Carb and Ketogenic Diets in Type 1 and Type 2 Diabetes. Nutrient 2019, 11, 962. [CrossRef] [PubMed]

72. Yancy, W.S.; Foy, M.; Chalecki, A.M.; Vernon, M.C.; Westman, E.C. A low-carbohydrate, ketogenic diet to treat type 2 diabetes. Nutr. Metab. 2005, 2, 34. [CrossRef]

73. Bolla, A.M.; Dozio, N.; Scavini, M.; Succurro, E.; Tumminia, A.; Torlone, E.; Sasso, F.C.; Vitacolonna, E. Awareness about diabetes and pregnancy among diabetes specialists and fellows: The YoSID diabetes and pregnancy project. Nutr. Metab. Cardiovasc. Diseases, 2020; 30, 1520-1524. [CrossRef]

74. Astrup, A.; Larsen, T.M.; Harper, A. Atkins and other low-carbohydrate diets: Hoax or an effective tool for weight loss? Lancet 2004, 364, 897-899. [CrossRef]

75. Goldstein, T.; Kark, J.D.; Berry, E.M.; Adler, B.; Ziv, E.; Raz, I. The effect of a low carbohydrate energy-unrestricted diet on weight loss in obese type 2 diabetes patients-A randomized controlled trial. e-SPEN Eur. e-J. Clin. Nutr. Metab. 2011, 6, e178-e186. [CrossRef]

76. Andrikopoulos, S. The Paleo diet and diabetes. Med. J. Aust. 2016, 205, 151-152. [CrossRef]

77. Tarantino, G.; Citro, V.; Finelli, C. Hype or Reality: Should Patients with Metabolic Syndrome-related NAFLD be on the Hunter-Gatherer (Paleo) Diet to Decrease Morbidity? J. Gastrointest. Liver Dis. 2015, 24, 359. [CrossRef]

78. Lindeberg, S.; Jönsson, T.; Granfeldt, Y.; Borgstrand, E.; Soffman, J.; Sjöström, K.; Ahrén, B. A Palaeolithic diet improves glucose tolerance more than a Mediterranean-like diet in individuals with ischaemic heart disease. Diabetology 2007, 50, $1795-1807$. [CrossRef]

79. Galbete, C.; Kröger, J.; Jannasch, F.; Iqbal, K.; Schwingshackl, L.; Schwedhelm, C.; Weikert, C.; Boeing, H.; Schulze, M.B. Nordic diet, Mediterranean diet, and the risk of chronic diseases: The EPIC-Potsdam study. BMC Med. 2018, 16, 99. [CrossRef] [PubMed]

80. Sacks, F.M.; Svetkey, L.P.; Vollmer, W.M.; Appel, L.J.; Bray, G.A.; Harsha, D.; Obarzanek, E.; Conlin, P.R.; Miller, E.R.; SimonsMorton, D.G.; et al. Effects on Blood Pressure of Reduced Dietary Sodium and the Dietary Approaches to Stop Hypertension (DASH) Diet. N. Engl. J. Med. 2001, 344, 3-10. [CrossRef] 
81. Morris, M.C.; Tangney, C.C.; Wang, Y.; Sacks, F.M.; Bennett, D.A.; Aggarwal, N.T. MIND diet associated with reduced incidence of Alzheimer's disease. Alzheimer's Dement. 2015, 11, 1007-1014. [CrossRef] [PubMed]

82. Sikalidis, A.K. From Food for Survival to Food for Personalized Optimal Health: A Historical Perspective of How Food and Nutrition Gave Rise to Nutrigenomics. J. Am. Coll. Nutr. 2018, 38, 84-95. [CrossRef] [PubMed] 